\title{
Race/ethnic differences in bone mineral densities in older men
}

\author{
H.-S. Nam • M.-H. Shin • J. M. Zmuda • P. C. Leung • \\ E. Barrett-Connor - E. S. Orwoll - J. A. Cauley • \\ Osteoporotic Fractures in Men (MrOS) Research Group
}

Received: 1 December 2009 /Accepted: 15 January 2010 /Published online: 4 March 2010

(C) The Author(s) 2010. This article is published with open access at Springerlink.com

\begin{abstract}
Summary BMD was compared across race/ethnic groups. There were substantial race/ethnic differences in BMD even within African or Asian origin. Additional adjustment for body size greatly attenuated or reversed the differences between US Caucasian men vs Asian men. It illustrates the role of body size on the difference between these groups. Introduction There is insufficient epidemiologic information about men's bone mineral density (BMD) levels across race/ethnic groups and geographic locations.
\end{abstract}

\section{H.-S. Nam}

Department of Preventive Medicine, Research Institute for Medical Sciences, Chungnam National University College of Medicine,

Daejeon, South Korea

H.-S. Nam · J. M. Zmuda · J. A. Cauley $(\bowtie)$

Department of Epidemiology, Graduate School of Public Health, University of Pittsburgh,

130 DeSoto Street, Crabtree Hall A524,

Pittsburgh, PA 15261, USA

e-mail: jcauley@edc.pitt.edu

\section{M.-H. Shin}

Department of Preventive Medicine, Chonnam National

University Medical School,

Gwangju, South Korea

\section{P. C. Leung}

Jockey Club Centre for Osteoporosis Care and Control,

Chinese University of Hong Kong, Prince of Wales Hospital,

Hong Kong, China

\section{E. Barrett-Connor}

Department of Family and Preventive Medicine,

University of California San Diego,

La Jolla, CA, USA

E. S. Orwoll

Bone and Mineral Unit, Oregon Health and Sciences University, Portland, OR, USA
Methods In a cross-sectional design, we compared BMD in older men across seven race/ethnic groups in four countries. Femoral neck, total hip, and lumbar spine BMD were measured in men (age 65 to 78 years) from the Osteoporotic Fractures in Men (MrOS) Study (4,074 Caucasian, 208 African-American, 157 Asian, and 116 Hispanic men in USA), Tobago Bone Health Study (422 Afro-Caribbean men), MrOS Hong Kong Study (1,747 Hong Kong Chinese men), and the Namwon Study (1,079 South Korean men). BMD was corrected according to the cross-site calibration results for all scanners.

Results When compared with US Caucasian men, AfroCaribbean and African-American men had, respectively, 8$20 \%$ and $6-11 \%$ higher age-adjusted mean BMD at all three bone sites. Hip BMD was similar in US Caucasian and Hispanic men, US Asian, Hong Kong Chinese, and Korean men had 3-14\% lower BMD at all bone sites except femoral neck in Korean men. Additional adjustment for weight and height greatly attenuated or reversed the differences between US Caucasian men vs Asian men including US Asian, Hong Kong Chinese, and South Korean men. Among Asian groups, Korean men had higher femoral neck BMD and lower total hip BMD.

Conclusion These findings show substantial race/ethnic differences in BMD even within African or Asian origin and illustrate the important role of body size on the difference between Asian men and others.

Keywords Body size - Bone densitometry Bone mineral density $\cdot$ Epidemiology $\cdot$ Men $\cdot$ Race/ethnicity

\section{Introduction}

Osteoporosis and fractures are important health problems in older men $[1,2]$. The lifetime risk of experiencing an 
osteoporotic fracture in Caucasian men over the age of 50 is similar to the lifetime risk of developing prostate cancer [2]. Mortality after an osteoporotic fracture is greater in older men compared to older women [3, 4]. Considering demographic trends leading to greater numbers of older men in both developed and developing countries, the societal burden of osteoporosis in men is a major international health concern.

Many studies in US people reported that hip fracture rates among older African-American, Asian, and Hispanic men are lower than rates among Caucasian men [5-11]. Several population studies have reported that AfricanAmerican men have higher bone mineral density (BMD) than US Caucasian and Hispanic men at major weightbearing sites such as femoral neck and lumbar spine [12-15]. Age-related cross-sectional declines in BMD have been shown to be significantly steeper among US Hispanic men than African-American or US Caucasian men [14, 15]. These race/ethnic differences in BMD could contribute to the lower risk of fracture in African-American men when compared to Caucasian and Hispanic men. However, the evidence of difference in BMD between US Hispanic and Caucasian men is not consistent [13-15], and the difference between Caucasian and Asian men is also inconclusive $[13,16,17]$.

Most epidemiologic reports on race/ethnic differences in men's BMD are limited to US race/ethnic groups. To extend our knowledge about race/ethnic difference in BMD, we collected datasets from one US [18] and three non-US bone health studies [19-21] and compared older men's mean BMD, respectively, across seven race/ethnic groups: US Caucasian, US Hispanic, US Asian, AfricanAmerican, Afro-Caribbean, Hong Kong Chinese, and South Korean.

\section{Materials and methods}

\section{Study subjects}

We used a cross-sectional design; the datasets included the Osteoporotic Fractures in Men (MrOS) Study [18], MrOS Hong Kong Study [19], Tobago Bone Health Study [20], and Namwon Study. Details on study subjects and measurements for these studies have been published [18-20] except Namwon Study. Briefly, the MrOS Study enrolled 5,995 men aged 65 or older at six US clinical settings in Birmingham, AL; Minneapolis, MN; the Monongahela Valley near Pittsburgh, PA; Palo Alto, CA; Portland, OR; and San Diego, CA from March 2000 to April 2002 $[18,22]$. The study included 5,362 Caucasian men, 244 African-American men, 191 Asian men, 127 Hispanic men, and 71 men of other race/ethnicity [18]. The MrOS Hong
Kong Study enrolled 2,000 Chinese men aged 65-92 [19]. In the Tobago Bone Health Study, 2,589 Afro-Caribbean men aged 40 or older were recruited from the Caribbean Island of Tobago during 2000-2004 [20].

The Namwon Study was designed to investigate the determinants of the occurrence and progression of cardiovascular disease, osteoporosis, and dementia in Namwon city, South Korea. The 2005 census reported 33,068 residents (14,960 men and 18,108 women) aged 45-74 in Namwon city. From 2004 to 2007, all eligible residents aged 45-74 were invited to participate through the mailing and telephone calling based on the list of officially registered residents. A total of 10,665 subjects $(4,200$ men and 6,465 women; response rate $32.3 \%$ ) had clinical examinations following interviews. Focusing on men aged 65-74, among 4,496 eligible men, there were 1,492 participants (response rate 33.2\%) who had hip or lumbar spine BMD measures by DPX Bravo $(n=483$; GE, Madison, WI) or Lunar Prodigy ( $n=10,091$; GE, Madison, WI) scanner. In addition to these participants, there were 94 men aged 75 and over who also lived in Namwon city and volunteered to participate. Only the Lunar Prodigy was available for the cross-calibration study. Thus, we limited our study to the 1,103 Korean men aged 65 and over with BMD by Lunar Prodigy.

All the studies recruited ambulatory subjects. All of the participants provided informed consent, and each study was conducted in accordance with the guidelines in the Declaration of Helsinki. Each study was approved by the appropriate institutional research ethics committee.

In the MrOS Study, race/ethnicity was self-declared using a single question indicating their background as one or more of the following: American Indian or Alaska Native, Asian, African-American or black, Hispanic or Latino, Native Hawaiian or other Pacific Islander, or White. Responses were classified into mutually exclusive "race/ ethnicity" categories as Hispanic, black, Asian, White, or other. In the Tobago Bone Health Study [20], participants provided detailed information on the ethnic ancestry of their parents and grandparents. Afro-Caribbean men were defined as men who reported four Afro-Caribbean grandparents; men with mixed Afro-Caribbean ancestry, i.e., men who had three or fewer Afro-Caribbean grandparents were excluded from the analysis. In the MrOS Hong Kong and the Namwon Study, participants were not asked about the ethnic ancestry because recruitment was limited to these specific ethnic groups.

For all race/ethnic groups, we restricted analyses to men aged 65 to 78 years who had BMD at the femoral neck, hip, or lumbar spine with complete age, weight, and height data. The upper and lower ages were restricted to allow comparability in age distribution: There were too few South Korean and US Hispanic men aged 79 or older 
( $<$ five men at each age level). We excluded subjects who reported any hormone therapy or orchiectomy to treat prostate cancer (69 US Caucasian, 6 African-American, 4 US Asian, 1 US Hispanic, 5 Hong Kong Chinese, 2 South Korean men, and 52 Afro-Caribbean men).

The final dataset included 4,074 US Caucasian, 208 African-American, 157 US Asian, 116 US Hispanic men from the MrOS Study, 422 Afro-Caribbean men, 1,747 Hong Kong Chinese men, and 1,079 Korean men.

\section{BMD measurements and cross-calibration}

Femoral neck, total hip, and total lumbar spine BMD (gram per square centimeter) were measured using Hologic QDR 4,500-W densitometer (Hologic Inc, Bedford, MA) in the MrOS Study, the MrOS Hong Kong Study, and the Tobago Bone Health Study and using Lunar Prodigy (GE, Madison, WI) in the Namwon Study. All BMD scans were conducted using standardized procedures following the manufacturer's recommended protocols. All DXA operators in each study were trained and certified. Longitudinal quality control was performed daily with a spine phantom and showed no shifts or drifts in each study site.

From 2002 to 2005, by the Musculoskeletal and Quantitative Imaging Research Group at the University of California, San Francisco (UCSF), cross-calibration studies were carried out using the Hologic spine, femur, and block phantoms for the scanners used in the MrOS Study (US sites; 2000), the MrOS Hong Kong Study (2002), and the Tobago Bone Health Study (2004). For this analysis, UCSF also carried out a cross-calibration procedure in 2008 using the same phantoms for the scanner of the Namwon Study. Since the sites included Lunar and Hologic scanners, BMD parameters were standardized (converted to sBMD) according to the formula published by Hui et al. [23]. Corrections for any statistically significant differences across scanners were then applied to participant spine, total hip, and femoral neck BMD values. BMD values for participants at the six US sites and Hong Kong sites, but not in Tobago or Korea, were also corrected for longitudinal shifts, based on Hologic spine phantom scanned during the visit on each densitometer. Details on the cross-calibration procedure were as follows.

Phantom scans were scanned five times each on the same day and were analyzed centrally by the same research assistant (MrOS, MrOS Hong Kong, Tobago) or locally (Korea) for each DXA scanner. To avoid edge effects, subregional analyses were used by UCSF to analyze all block phantom scans. One MrOS US site was considered the reference site. The phantom BMD results were first converted to sBMD [23]. In order to derive the linearity of each machine, linear regression was used in analyzing the block phantom results. The ratio between the study site and the reference site (reference site/measurement site) for sBMD was then calculated. ANOVA with a Dunnet test was applied to determine the mean sBMD difference between the study site and the reference site. If the sBMD for a study site was significantly different from the reference site, the ratio was used as the cross-calibration factors for each specific scan type. Otherwise, the cross-calibration factor was set to 1 .

\section{Other measurements}

Information on demographics, lifestyle, medical history, and self-reported health was obtained by trained interviewer with questionnaires in each study.

Smoking status was categorized as current, past, or never, and life time smoking amount was computed as the unit of pack-year. Current alcohol consumption was calculated as drinks per week. Physical activity was measured by the Physical Activity Scale for Elderly Questionnaire [24] in all studies except the Namwon and Tobago Bone Health Studies. In the Tobago Bone Health Study, participants were asked about the frequency of walking outside. Because of the difference in questionnaires among studies, we used only one common variable, the frequency of walking outside home per week. This was classified as often (5-7 days/week) and otherwise. In the Namwon Study, physical activity was measured by Baecke's questionnaire. Korean men were asked two questions about the frequency of walking during leisure time or at work [25]. If a man answered at least one question as "often" or "always," the frequency of walking outside per week was coded as "often." Dietary calcium intake was calculated by the food frequency questionnaires specific for each country: the modified versions of the Block Food Frequency Questionnaire in the MrOS Study [26], the MrOS Hong Kong Study [19], the Tobago Bone Health Study [27], and the food frequency questionnaire developed for the Korean Genome Epidemiologic Study [28] in the Namwon Study.

Information on hormonal and surgical treatments for prostate cancer was identified. All studies assessed selfreported health status with the same categories as excellent, good, fair, poor, and very poor. The variable was classified as excellent/good and otherwise.

Body weight was measured in indoor clothing or light gown without shoes using a calibrated Inbody 3.0 (Biospace Co. Korea) in the Namwon Study, a calibrated digital scale in one site (Portland) of the MrOS Study and calibrated balanced beam scales in the five sites of MrOS Study, the MrOS Hong Kong Study, and the Tobago Bone Health Study. Standing height was measured using a stadiometer in each study. Body mass index (BMI) was 
calculated by dividing body weight (kilograms) by square height (square meter).

Statistical analysis

Descriptive data for the major characteristics and BMD values are expressed as percentage or mean \pm standard deviation (SD). BMD was compared across race/ethnic groups after adjustment with age only, with age, height, and weight using general linear model (GLM). In addition to these variables, we examined smoking amount, current alcohol consumption, walking, dietary calcium intake, and self-reported health as potential confounders. When these variables were added separately in the previous GLM including age, height, and weight, all variables were significantly $(p<0.05)$ associated with femoral neck BMD. Therefore, they were included as covariates in the full model. Least square means of BMD (LSMs) among race/ethnic groups were estimated by the multivariable GLMs, and the percentage differences in LSMs between US Caucasian men and other race/ethnic groups were calculated. Tukey-Kramer adjustment was applied to correct for pairwise comparisons. Results were considered statistically significant when $p$ values were less than 0.05 , and all $p$ values less than 0.1 were shown. SAS software version 9.2 (SAS Institute, Cary, NC) was used for all statistical analyses.

\section{Results}

Demographic and lifestyle characteristics

Table 1 shows the demographic and lifestyle characteristics across race/ethnic groups. Compared with US Caucasian men, US Hispanic, US Asian, and Hong Kong Chinese men had similar mean age; Afro-Caribbean and Korean men were slightly younger. African-American men had similar weight and height compared to US Caucasian men. Afro-Caribbean and US Asian men weighed less and were shorter than US Caucasian men. Hong Kong Chinese and Korean men weighed less and were shorter than other race/ethnic groups. BMI was lower in all Asian ethnic groups. The range of BMI differed across race/ethnic groups. Few men (1.4\% to $5.1 \%)$ among the three Asian ethnic groups were obese (BMI> $\left.30 \mathrm{~kg} / \mathrm{m}^{2}\right)$. The two non-US Asian groups had a higher proportion $(11.5 \%$ to $12.7 \%)$ of men with $\mathrm{BMI}<20$. On the other hand, a substantial proportion $(22.0 \%$ to $33.2 \%)$ of men among US Caucasian, African-American, Afro-

Table 1 Baseline characteristics of participants according to race/ethnic group

\begin{tabular}{|c|c|c|c|c|c|c|c|}
\hline & $\begin{array}{l}\text { US } \\
\text { Caucasian }\end{array}$ & $\begin{array}{l}\text { Tobago } \\
\text { Afro-Caribbean }\end{array}$ & $\begin{array}{l}\text { African- } \\
\text { American }\end{array}$ & US Hispanic & US Asian & $\begin{array}{l}\text { Hong Kong } \\
\text { Chinese }\end{array}$ & $\begin{array}{l}\text { South } \\
\text { Korean }\end{array}$ \\
\hline Sample size ${ }^{a}$ & $N=4,074$ & $N=419$ & $N=208$ & $N=116$ & $N=157$ & $N=1,747$ & $N=1,079$ \\
\hline Age (years) & $71.3 \pm 3.9 \mathrm{c}, \mathrm{d}$ & $70.2 \pm \pm 3.8 \mathrm{a}, \mathrm{b}$ & $70.4 \pm 3.9 \mathrm{a}, \mathrm{b}, \mathrm{c}$ & $71.2 \pm 3.8 \mathrm{c}, \mathrm{d}$ & $71.4 \pm 3.9 \mathrm{~d}$ & $71.1 \pm 3.7 \mathrm{~b}, \mathrm{c}, \mathrm{d}$ & $70.0 \pm 3.2 \mathrm{a}$ \\
\hline Weight (kg) & $85.1 \pm 13.0 \mathrm{~d}, \mathrm{e}$ & $81.2 \pm 14.1 \mathrm{c}$ & $87.1 \pm 15.3 \mathrm{e}$ & $82.2 \pm 13.5 \mathrm{c}, \mathrm{d}$ & $70.3 \pm 9.3 \mathrm{~b}$ & $62.8 \pm 9.3 \mathrm{a}$ & $61.8 \pm 9.1 \mathrm{a}$ \\
\hline Standing height $(\mathrm{cm})$ & $175.2 \pm 6.5 \mathrm{e}$ & $172.7 \pm 6.6 \mathrm{~d}$ & $174.5 \pm 7.3 \mathrm{e}$ & $170.5 \pm 6.4 \mathrm{c}$ & $167.2 \pm 5.9 \mathrm{~b}$ & $163.2 \pm 5.6 \mathrm{a}$ & $163.0 \pm 5.8 \mathrm{a}$ \\
\hline BMI $\left(\mathrm{kg} / \mathrm{m}^{2}\right)$ & $27.7 \pm 3.8 \mathrm{c}, \mathrm{d}$ & $27.2 \pm 4.4 \mathrm{c}$ & $28.5 \pm 4.3 \mathrm{~d}$ & $28.2 \pm 3.9 \mathrm{~d}$ & $25.1 \pm 3.0 \mathrm{~b}$ & $23.6 \pm 3.1 \mathrm{a}$ & $23.2 \pm 2.9 \mathrm{a}$ \\
\hline$>30(\%)$ & 23.4 & 22.0 & 33.2 & 26.7 & 5.1 & 2.0 & 1.4 \\
\hline$<20(\%)$ & 0.6 & 2.6 & 1.4 & 0.9 & 3.2 & 11.5 & 13.1 \\
\hline \multicolumn{8}{|l|}{ Smoking } \\
\hline Current (\%) & 3.8 & 7.2 & 12.0 & 2.6 & 3.2 & 12.3 & 29.9 \\
\hline Past $(\%)$ & 60.4 & 26.5 & 53.9 & 59.5 & 52.9 & 50.5 & 53.7 \\
\hline Pack-years & $19.3 \pm 25.3 \mathrm{c}$ & $7.5 \pm 18.7 \mathrm{a}$ & $18.0 \pm 23.7 \mathrm{~b}, \mathrm{c}$ & $12.3 \pm 18.3 \mathrm{a}, \mathrm{b}$ & $12.3 \pm 19.5 \mathrm{a}, \mathrm{b}$ & $20.3 \pm 28.6 \mathrm{c}$ & $28.1 \pm 24.1 \mathrm{~d}$ \\
\hline Drinking (drinks/week) & $4.6 \pm 7.1 \mathrm{c}$ & $1.1 \pm 3.5 \mathrm{a}$ & $3.4 \pm 7.2 \mathrm{~b}, \mathrm{c}$ & $5.2 \pm 7.4 \mathrm{c}$ & $2.2 \pm 4.7 \mathrm{a}, \mathrm{b}$ & $0.9 \pm 4.0 \mathrm{a}$ & $11.7 \pm 19.8 \mathrm{~d}$ \\
\hline \multicolumn{8}{|l|}{ Walking outside } \\
\hline 5-7 days/week (\%) & 48.3 & 62.1 & 34.1 & 49.1 & 46.5 & 93.9 & 68.2 \\
\hline $\begin{array}{l}\text { Dietary calcium intake } \\
\text { (mg/day) } \\
\text { Self-reported health }\end{array}$ & $811.6 \pm 389.2 \mathrm{~d}$ & $439.8 \pm 218.8 \mathrm{~b}$ & $652.9 \pm 365.0 \mathrm{c}$ & $662.2 \pm 314.5 \mathrm{c}$ & $616.0 \pm 318.8 \mathrm{c}$ & $630.1 \pm 295.8 \mathrm{c}$ & $323.1 \pm 188.6 \mathrm{a}$ \\
\hline Fair or poor $(\%)$ & 13.5 & 16.3 & 21.2 & 14.7 & 17.8 & 42.2 & 56.0 \\
\hline
\end{tabular}

$\mathrm{a}, \mathrm{b}, \mathrm{c}, \mathrm{d}, \mathrm{e}=$ These lowercase letters show the results of pairwise comparison by Tukey test: If a pair does not share any footnote, both groups are significantly different in the test variable $(p<0.05)$

${ }^{\text {a }}$ Sample size is based on the number of men with no missing values for hip BMD, age, weight, or height 
Caribbean, and US Hispanic groups were obese, and few men $(0.6 \%$ to $2.6 \%)$ had low body weight $\left(\mathrm{BMI}<20 \mathrm{~kg} / \mathrm{m}^{2}\right)$.

Current smoking was highest among Korean men and lowest among US men, but more than $50 \%$ of all men except Afro-Caribbeans reported past smoking. Korean men also reported much greater alcohol consumption compared to other groups. Most men reported walking at least five times per week, especially among Hong Kong men. Dietary calcium intake was greatest in US Caucasian men and lowest in Korean men. Compared with US Caucasian men, Korean, Hong Kong Chinese, and African-American men were more likely to report their health status as fair or poor (Table 1).
Differences in BMD among race/ethnic groups

Table 2 shows the crude and adjusted mean BMD at the femoral neck, total hip, and lumbar spine. Figures 1 and 2 present percentage differences in the adjusted mean BMD at each site among race/ethnic groups compared with Caucasian.

When compared with US Caucasian men, age-adjusted mean BMD measures at all three BMD sites were $8-20 \%$ higher among Afro-Caribbean and 6-12\% higher among African-American men. Hip BMD was similar among US Caucasian and Hispanic men, but spine BMD was $3 \%$ lower among Hispanic men. Hip and spine BMD values

Table 2 Comparison of BMD at each site among race/ethnic groups

\begin{tabular}{|c|c|c|c|c|c|c|c|}
\hline & $\begin{array}{l}\text { US } \\
\text { Caucasian }\end{array}$ & $\begin{array}{l}\text { Tobago } \\
\text { Afro-Caribbean }\end{array}$ & $\begin{array}{l}\text { African- } \\
\text { American }\end{array}$ & $\begin{array}{l}\text { US } \\
\text { Hispanic }\end{array}$ & US Asian & $\begin{array}{l}\text { Hong Kong } \\
\text { Chinese }\end{array}$ & $\begin{array}{l}\text { South } \\
\text { Korean }\end{array}$ \\
\hline Femoral neck BMD $\left(\mathrm{g} / \mathrm{cm}^{2}\right)$ & $(N=4,074)$ & $(N=419)$ & $(N=208)$ & $(N=116)$ & $(N=157)$ & $(N=1,747)$ & $(N=1,079)$ \\
\hline Crude mean (SD) & $0.853(0.130)$ & $1.026(0.155)$ & $0.953(0.157)$ & $0.868(0.127)$ & $0.822(0.119)$ & $0.796(0.119)$ & $0.846(0.117)$ \\
\hline Age-adjusted mean (SE) & $0.854(0.002)$ & $1.023(0.006)$ & $0.951(0.009)$ & $0.869(0.012)$ & $0.824(0.010)$ & $0.796(0.003)$ & $0.841(0.004)$ \\
\hline Pairwise comparison & $\mathrm{c}$ & $\mathrm{a}$ & $\mathrm{b}$ & $\mathrm{c}$ & $\mathrm{c}, \mathrm{d}$ & d & $\mathrm{c}$ \\
\hline Adjusted mean $(\mathrm{SE})^{\mathrm{a}}$ & $0.820(0.002)$ & $1.006(0.006)$ & $0.911(0.008)$ & $0.846(0.011)$ & $0.846(0.009)$ & $0.848(0.003)$ & $0.898(0.004)$ \\
\hline Adjusted mean $(\mathrm{SE})^{\mathrm{b}}$ & $0.822(0.002)$ & $1.006(0.006)$ & $0.912(0.008)$ & $0.845(0.011)$ & $0.845(0.009)$ & $0.845(0.003)$ & $0.896(0.004)$ \\
\hline Pairwise comparison $^{\mathrm{b}}$ & $\mathrm{d}$ & a & $\mathrm{b}$ & $\mathrm{c}, \mathrm{d}$ & $\mathrm{c}, \mathrm{d}$ & $\mathrm{c}$ & $\mathrm{b}$ \\
\hline Adjusted mean $(\mathrm{SE})^{\mathrm{c}}$ & $0.820(0.002)$ & $1.008(0.006)$ & $0.917(0.008)$ & $0.843(0.011)$ & $0.848(0.010)$ & $0.849(0.004)$ & $0.906(0.005)$ \\
\hline Pairwise comparison $^{\mathrm{c}}$ & $\mathrm{d}$ & a & $\mathrm{b}$ & $\mathrm{c}, \mathrm{d}$ & $\mathrm{c}, \mathrm{d}$ & $\mathrm{c}$ & $\mathrm{b}$ \\
\hline Total hip BMD $\left(\mathrm{g} / \mathrm{cm}^{2}\right)$ & $(N=4,074)$ & $(N=419)$ & $(N=208)$ & $(N=116)$ & $(N=157)$ & $(N=1,747)$ & $(N=1,079)$ \\
\hline Crude mean (SD) & $1.039(0.142)$ & $1.205(0.160)$ & $1.119(0.165)$ & $1.043(0.142)$ & $0.988(0.118)$ & $0.962(0.133)$ & $0.894(0.126)$ \\
\hline Age-adjusted mean (SE) & $1.041(0.002)$ & $1.202(0.007)$ & $1.116(0.010)$ & $1.044(0.013)$ & $0.990(0.011)$ & $0.963(0.003)$ & $0.890(0.004)$ \\
\hline Pairwise comparison & $\mathrm{c}$ & $\mathrm{a}$ & $\mathrm{b}$ & $\mathrm{c}$ & d & d & $\mathrm{e}$ \\
\hline Adjusted mean $(\mathrm{SE})^{\mathrm{a}}$ & $0.999(0.002)$ & $1.181(0.006)$ & $1.068(0.009)$ & $1.016(0.012)$ & $1.017(0.010)$ & $1.026(0.003)$ & $0.960(0.004)$ \\
\hline Adjusted mean $(\mathrm{SE})^{\mathrm{b}}$ & $1.003(0.002)$ & $1.183(0.006)$ & $1.070(0.009)$ & $1.014(0.012)$ & $1.015(0.010)$ & $1.021(0.004)$ & $0.955(0.004)$ \\
\hline Pairwise comparison $^{\mathrm{b}}$ & $\mathrm{d}$ & $\mathrm{a}$ & $\mathrm{b}$ & $\mathrm{c}, \mathrm{d}$ & $\mathrm{c}, \mathrm{d}$ & $\mathrm{c}$ & $\mathrm{e}$ \\
\hline Adjusted mean $(\mathrm{SE})^{\mathrm{c}}$ & $0.999(0.002)$ & $1.185(0.007)$ & $1.073(0.009)$ & $1.010(0.012)$ & $1.017(0.010)$ & $1.026(0.004)$ & $0.968(0.005)$ \\
\hline Pairwise comparison $^{c}$ & $\mathrm{~d}$ & $\mathrm{a}$ & $\mathrm{b}$ & $\mathrm{c}, \mathrm{d}$ & $\mathrm{c}, \mathrm{d}$ & $\mathrm{c}$ & $\mathrm{e}$ \\
\hline Lumbar spine BMD $\left(\mathrm{g} / \mathrm{cm}^{2}\right)$ & $(\mathrm{N}=4,068)$ & $(\mathrm{N}=422)$ & $(\mathrm{N}=208)$ & $(\mathrm{N}=116)$ & $(\mathrm{N}=157)$ & $(\mathrm{N}=1,724)$ & $(\mathrm{N}=1,052)$ \\
\hline Crude mean (SD) & $1.140(0.190)$ & $1.231(0.196)$ & $1.208(0.220)$ & $1.106(0.193)$ & $1.107(0.174)$ & $1.024(0.185)$ & $1.050(0.192)$ \\
\hline Age-adjusted mean (SE) & $1.139(0.003)$ & $1.232(0.009)$ & $1.209(0.013)$ & $1.106(0.018)$ & $1.107(0.015)$ & $1.024(0.005)$ & $1.051(0.006)$ \\
\hline Pairwise comparison & $\mathrm{b}$ & a & $\mathrm{a}$ & $\mathrm{b}$ & $\mathrm{b}$ & $\mathrm{c}$ & d \\
\hline Adjusted mean $(\mathrm{SE})^{\mathrm{a}}$ & $1.104(0.003)$ & $1.213(0.009)$ & $1.167(0.013)$ & $1.082(0.017)$ & $1.131(0.015)$ & $1.080(0.005)$ & $1.113(0.006)$ \\
\hline Adjusted mean $(\mathrm{SE})^{\mathrm{b}}$ & $1.101(0.003)$ & $1.212(0.009)$ & $1.166(0.013)$ & $1.083(0.017)$ & $1.133(0.015)$ & $1.084(0.005)$ & $1.117(0.006)$ \\
\hline Pairwise comparison $^{\mathrm{b}}$ & $\mathrm{c}, \mathrm{d}$ & $\mathrm{a}$ & $\mathrm{b}$ & $\mathrm{c}, \mathrm{d}$ & $\mathrm{b}, \mathrm{c}$ & d & $\mathrm{c}$ \\
\hline Adjusted mean $(\mathrm{SE})^{\mathrm{c}}$ & $1.099(0.004)$ & $1.209(0.009)$ & $1.167(0.013)$ & $1.080(0.017)$ & $1.134(0.015)$ & $1.090(0.006)$ & $1.125(0.008)$ \\
\hline Pairwise comparison $^{c}$ & $\mathrm{c}, \mathrm{d}$ & $\mathrm{a}$ & $\mathrm{a}, \mathrm{b}$ & $\mathrm{c}, \mathrm{d}$ & $\mathrm{b}, \mathrm{c}, \mathrm{d}$ & $\mathrm{d}$ & $\mathrm{b}, \mathrm{c}$ \\
\hline
\end{tabular}

$\mathrm{a}, \mathrm{b}, \mathrm{c}, \mathrm{d}, \mathrm{e}=$ These lowercase letters show the results of pairwise comparison by Tukey's test: If a pair does not share any footnote, both groups are significantly different in BMD $(p<0.05)$

${ }^{a}$ Adjusted for age and weight

${ }^{\mathrm{b}}$ Adjusted for age, weight, and height

${ }^{\mathrm{c}}$ Adjusted for age, weight, height, smoking, drinking, walking, dietary calcium intake, and self-reported health 
Fig. 1 Percentage differences in age-adjusted mean of BMD among Afro-Caribbean, African-American, US Hispanic, US Asian, Hong Kong Chinese, and South Korean men compared with US Caucasian men 65 years or older. $* p=0.057$, $* * p<0.001$ by Tukey's test comparing BMD between US Caucasian men and each race/ethnic group

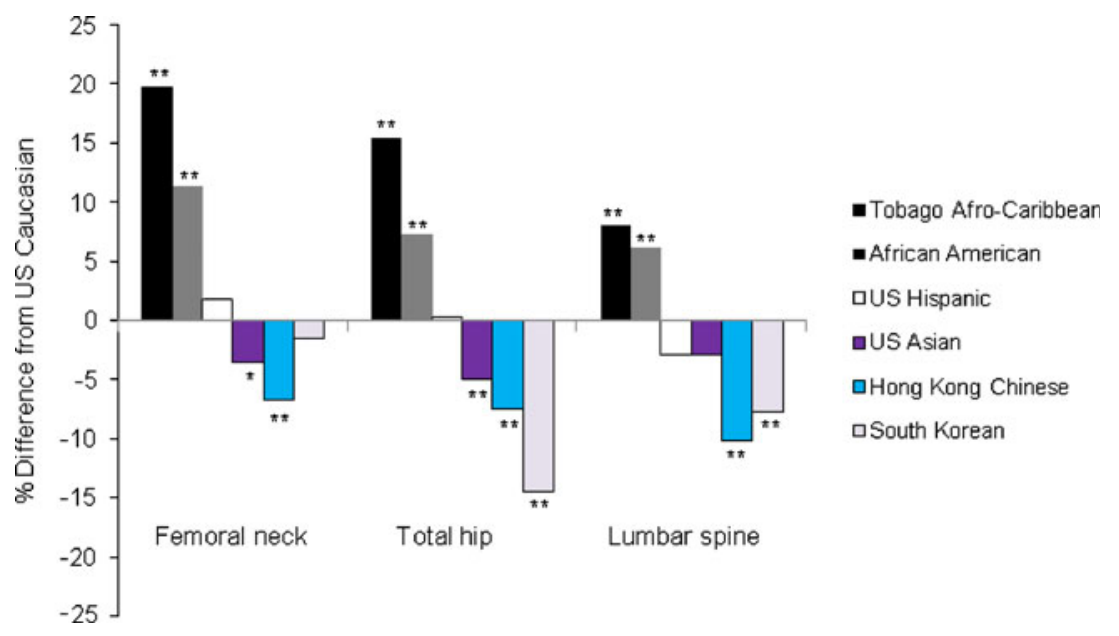

were 3-5\% lower among US Asian, 7-10\% lower among Hong Kong Chinese, and 8-14\% lower except femoral neck among Korean men compared to US Caucasians. The differences shown above were statistically significant $(p<$ 0.001 ) or nearly significant $(p=0.057$ for femoral neck in Asian men) except for spine BMD in Hispanic or Asian men (Table 2; Fig. 1).

After additional adjustment for weight and height, differences in mean BMD at each site between Caucasian men vs African-American men or Afro-Caribbean men persisted. However, this adjustment greatly attenuated the differences in BMD between US Caucasian men and Asian ethnic groups such as US Asian, Hong Kong Chinese, and Korean men (Table 2; Fig. 2). Afro-Caribbean men had higher adjusted BMD at all sites than African-American men. Among Asian groups, US Asian and Hong Kong Chinese men had similar BMD at hip sites, but Korean men had higher BMD at femoral neck and lower BMD at total hip. Hong Kong Chinese men had lower spine BMD than other Asian groups.
Additional adjustment with lifestyle factors showed only minor changes $(-0.1 \sim 0.9 \%$ point $)$ in the percentage differences between Caucasian men vs each race/ethnic group except those at hip sites between Caucasian men vs Korean men $(1.9 \%$ point; Table 2).

\section{Discussion}

We compared hip and spine BMD in men of seven race/ ethnic groups and five countries. Our results indicate that there are substantial differences in age-adjusted BMD across race/ethnic groups and countries. In age-adjusted analysis, total hip BMD distributed across Five strata: AfroCaribbean men had the highest level; African-American men in the second; US Caucasian and US Hispanic in the third; US Asian and Hong Kong Chinese in the fourth; and Korean men had the lowest level. Although age-related change in osteophytic calcification might affect spine DXA measures, similar patterns were observed for lumbar spine
Fig. 2 Percentage differences in age-, weight-, and heightadjusted mean of BMD among Afro-Caribbean, AfricanAmerican, US Hispanic, US Asian, Hong Kong Chinese, and South Korean men compared with US Caucasian men 65 years or older. ${ }^{*} p<0.01$, $* * p<0.001$ by Tukey's test comparing BMD between US Caucasian men and each race/ethnic group

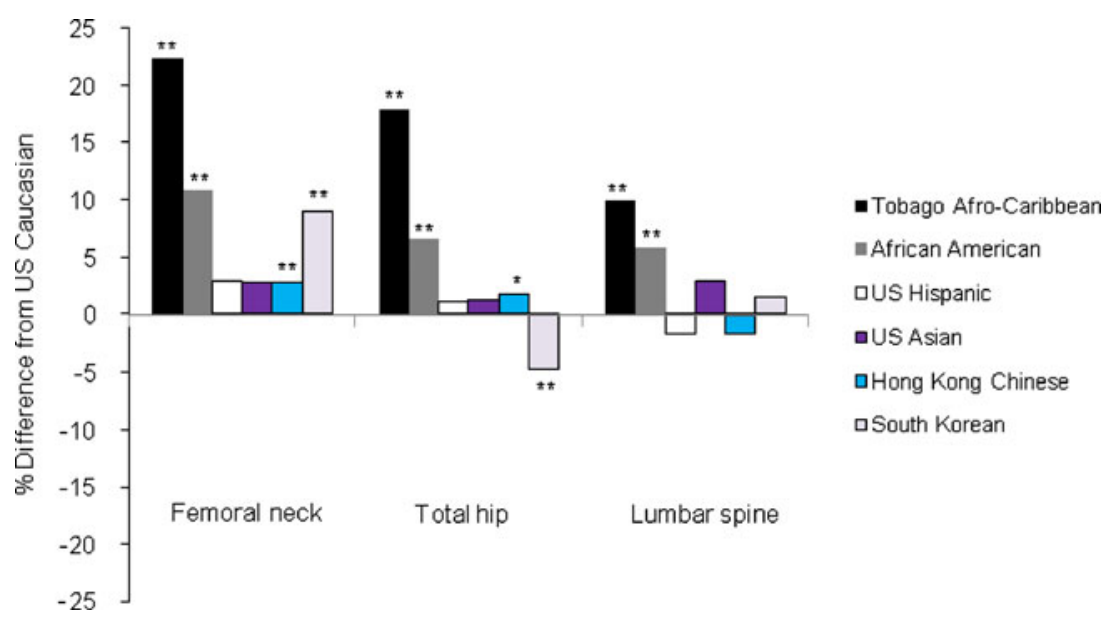


BMD as well as femoral neck except for Korean men. Unlike total hip BMD, femoral neck BMD among Korean men was similar to Caucasian men.

Identification of the BMD differences across race/ ethnicity and geography has important implication for understanding geographic variability in fracture risk. In general, hip BMD is strongly associated with the risk of nonvertebral fracture in older men [29,30]. Differences in age-adjusted BMD among Asian groups are consistent with the wide variability in fracture rates across Asian countries in the Asian Osteoporosis Study (AOS) [31]. The reported hip fracture rate among Korean men aged 70 to 79 (325 per $10^{5}$ men in 2004) [32] is slightly higher than Hong Kong Chinese men in AOS and is compatible with the difference in total hip BMD among both groups in our study. However, total hip BMD across some race/ethnic groups in our study is not compatible with previous reports [5-11] showing that fracture rates are lower in US Hispanic and Asian men than in Caucasian men. This paradox in Asian men may be in part attributable to more favorable hip geometry (the shorter hip axis length and smaller neck shaft angle) [33] and bone structure (greater cortical thickness and trabecular volumetric BMD) [34] among this group than Caucasian men. In addition to these factors, different fall rates [35] across race/ethnic groups can be involved in that paradox.

The differences in BMD depend both on genetic and environmental factors across countries and race/ethnic groups [36]. The environmental factors include social factors, as well as lifestyle factors, that could influence BMD within each community. For example, the prominent differences in total hip BMD between Korean and other Asian groups suggest differences in lifestyle and social factors in part. As shown in Table 1, the lower amount of calcium intake in Korean men may contribute to the lower total hip BMD: The difference in total hip BMD between Korean and Hong Kong Chinese men was smaller after adding dietary calcium intake into the regression model including age, weight, and height as covariates. Furthermore, the Korean men experienced relative nutritional deficits during Korean War (1950-1953) in their childhood or adolescence and might have led to lower peak skeletal mass [21]. However, the possible genetic influence on the difference among Asian groups should also be considered.

Consistent with the report of Hill et al. [20], AfroCaribbean men had 10-11\% higher hip BMD than AfricanAmerican men. Hill et al. [20] suggested two possible explanations for higher BMD in Afro-Caribbean men: Firstly, the proportion of European admixture (25\%) among African-American men is more than in Tobago $(6 \%)$; secondly, Tobago people have more weight-bearing activities due to the lack of industrialization than US people. As shown in Table 2, there was no change of the difference in BMD among both African origin groups before and after additional adjustment for lifestyle factors including walking. Considering this, it is thought that the proportion of European admixture is more responsible for the difference than weight-bearing activities.

The difference in BMD between US Caucasian men vs Asian groups may be explained to a great extent by body size [13, 16], although additional factors may also contribute. Body size has two kinds of implications for BMD. First, it has weight-bearing effects. The range of weight is quite different between Asian and non-Asian groups. Second, height and weight may in part correct for the confounding effect caused by bone size difference between both groups. In previous studies [16, 17], bone mineral apparent density (BMAD) measurements have been used to correct for the differences in bone size. However, recent evidence [37] suggests that BMAD may not address bone size differences appropriately when race/ethnic groups differ in body size. Moreover, there has been no evidence that estimates of BMAD improve fracture prediction more than using BMD [38].

US Hispanic and US Caucasian men had similar total hip BMD regardless of body size. Travison et al. [15] also showed the similarity in femoral neck BMD between both race/ethnic groups, but NHANES III reported 4.9-5.8\% higher femoral neck BMD at age 60-69 and 70-79 in Hispanic men than White men. The lack of clear-cut Hispanic-White differences in BMD may reflect the diversity among Hispanic subpopulations due to differences in admixture and acculturation [15].

There are several limitations to our study. Firstly, due to the smaller number of US Hispanic and US Asian men, we had limited power to find statistically significant differences between these groups and Caucasian men.

Secondly, since South Korean subjects were from one area in South Korea, BMD value of this group could be biased from the general Korean populations. However, our South Korean group is very similar in major characteristics to the same aged group from the Korea NHANES, a national health survey. The absolute difference is only $1.1 \mathrm{~cm}$ in height, $0.1 \mathrm{~kg}$ in weight, and $0.2 \%$ in the proportion of current smokers between the Namwon Study and Korea NHANES 2007, and 0.2 drinks per week in alcohol consumption between this study and Korea NHANES 2005, respectively. Therefore, the Korean men's mean BMD in this study is thought to be similar to the national value.

Thirdly, the manufacturer of the DXA scanner for Korean men was different than that for other race/ethnic groups. Lunar scanners are likely to overestimate the nominal BMD, while Hologic scanners underestimate it $[39,40]$. To remove this bias, we used sBMD [23] in the 
cross-calibration procedure, which is specific for scanner manufacturer. Cross-calibration for Korean scanner was done by the quality assurance group who had also calibrated the MrOS scanners and the Hong Kong and Tobago scanners. Correction factors were systematically applied to each scanner. In spite of this procedure, femoral neck BMD results in Korean men compared to other race/ ethnic groups were not consistent to those at other bone sites.

Lastly, we could not adjust for sun exposure factors such as latitude, urban/rural area, and outdoor activity, but we hope to measure serum 25-hydroxyvitamin D levels for all ethnic groups in a future study.

\section{Conclusion}

Our findings show substantial race/ethnic differences in BMD even within men of African or Asian origin and illustrate the important role of body size on the difference between Asian men and others.

Acknowledgments This work was supported by the Korea Research Foundation Grant funded by the Korean Government (MOEHRD, Basic Research Promotion Fund; KRF-2008-013-E00011). The Osteoporotic Fractures in Men (MrOS) Study is supported by National Institutes of Health funding. The following institutes provide support: the National Institute of Arthritis and Musculoskeletal and Skin Diseases (NIAMS), the National Institute on Aging (NIA), the National Center for Research Resources (NCRR), and NIH Roadmap for Medical Research under the following grant numbers: U01 AR45580, U01 AR45614, U01 AR45632, U01 AR45647, U01 AR45654, U01 AR45583, U01 AG18197, U01-AG027810, and UL1 RR024140. The Tobago Bone Health Study was supported by NIAMS grant R01-AR049747 and National Cancer Institute grant R01-CA84950.

Conflicts of interest This work was supported by the Korea Research Foundation Grant funded by the Korean Government.

Open Access This article is distributed under the terms of the Creative Commons Attribution Noncommercial License which permits any noncommercial use, distribution, and reproduction in any medium, provided the original author(s) and source are credited.

\section{References}

1. Cummings SR, Melton LJ (2002) Epidemiology and outcomes of osteoporotic fractures. Lancet 359:1761-1767

2. Cauley JA (2002) The determinants of fracture in men. J Musculoskelet Neuronal Interact 2:220-221

3. Jacobsen SJ, Goldberg J, Miles TP, Brody JA, Stiers W, Rimm AA (1992) Race and sex differences in mortality following fracture of the hip. Am J Public Health 82:1147-1150

4. Center JR, Nguyen TV, Schneider D, Sambrook PN, Eisman JA (1999) Mortality after all major types of osteoporotic fracture in men and women: an observational study. Lancet 353:878-882

5. Silverman SL, Madison RE (1988) Decreased incidence of hip fracture in Hispanics, Asians, and Blacks: California Hospital Discharge Data. Am J Public Health 78:1482-1483
6. Kellie SE, Brody JA (1990) Sex-specific and race-specific hip fracture rates. Am J Public Health 80:326-328

7. Jacobsen SJ, Goldberg J, Miles TP, Brody JA, Stiers W, Rimm AA (1990) Hip fracture incidence among the old and very old: a population-based study of 745,435 cases. Am J Public Health 80:871-873

8. Ross PD, Norimatsu H, Davis JW, Yano K, Wasnich RD, Fujiwara S, Hosoda Y, Melton LJ 3rd (1991) A comparison of hip fracture incidence among native Japanese, Japanese Americans, and American Caucasians. Am J Epidemiol 133:801-809

9. Lauderdale DS, Jacobsen SJ, Furner SE, Levy PS, Brody JA, Goldberg J (1997) Hip fracture incidence among elderly AsianAmerican populations. Am J Epidemiol 146:502-509

10. Lauderdale DS, Jacobsen SJ, Furner SE, Levy PS, Brody JA, Goldberg J (1998) Hip fracture incidence among elderly Hispanics. Am J Public Health 88:1245-1247

11. Fang J, Freeman R, Jeganathan R, Alderman MH (2004) Variations in hip fracture hospitalization rates among different race/ethnicity groups in New York City. Ethn Dis 14:280-284

12. Tracy JK, Meyer WA, Flores RH, Wilson PD, Hochberg MC (2005) Racial differences in rate of decline in bone mass in older men: the Baltimore men's osteoporosis study. J Bone Miner Res 20:1228-1234

13. Cauley JA, Fullman RL, Stone KL, Zmuda JM, Bauer DC, Barrett-Connor E, Ensrud K, Lau EM, Orwoll ES (2005) Factors associated with the lumbar spine and proximal femur bone mineral density in older men. Osteoporos Int 16:1525-1537

14. Araujo AB, Travison TG, Harris SS, Holick MF, Turner AK, McKinlay JB (2007) Race/ethnic differences in bone mineral density in men. Osteoporos Int 18:943-953

15. Travison TG, Beck TJ, Esche GR, Araujo AB, McKinlay JB (2008) Age trends in proximal femur geometry in men: variation by race and ethnicity. Osteoporos Int 19:277-287

16. Lau EM, Lynn H, Woo J, Melton LJ 3rd (2003) Areal and volumetric bone density in Hong Kong Chinese: a comparison with Caucasians living in the United States. Osteoporos Int 14:583-588

17. Wang XF, Duan Y, Beck TJ, Seeman E (2005) Varying contributions of growth and ageing to racial and sex differences in femoral neck structure and strength in old age. Bone 36:978-986

18. Orwoll E, Blank JB, Barrett-Connor E, Cauley J, Cummings S, Ensrud K, Lewis C, Cawthon PM, Marcus R, Marshall LM, McGowan J, Phipps K, Sherman S, Stefanick ML, Stone K (2005) Design and baseline characteristics of the osteoporotic fractures in men (MrOS) study - a large observational study of the determinants of fracture in older men. Contemp Clin Trials 26:569585

19. Lau EM, Leung PC, Kwok T, Woo J, Lynn H, Orwoll E, Cummings S, Cauley J (2006) The determinants of bone mineral density in Chinese men - results from Mr. Os (Hong Kong), the first cohort study on osteoporosis in Asian men. Osteoporos Int 17:297-303

20. Hill DD, Cauley JA, Sheu Y, Bunker CH, Patrick AL, Baker CE, Beckles GL, Wheeler VW, Zmuda JM (2008) Correlates of bone mineral density in men of African ancestry: the Tobago bone health study. Osteoporos Int 19:227-234

21. Cui LH, Choi JS, Shin MH, Kweon SS, Park KS, Lee YH, Nam HS, Jeong SK, Im JS (2008) Prevalence of osteoporosis and reference data for lumbar spine and hip bone mineral density in a Korean population. J Bone Miner Metab 26:609-617

22. Blank JB, Cawthon PM, Carrion-Petersen ML, Harper L, Johnson JP, Mitson E, Delay RR (2005) Overview of recruitment for the osteoporotic fractures in men study (MrOS). Contemp Clin Trials 26:557-568

23. Hui SL, Gao S, Zhou XH, Johnston CC Jr, Lu Y, Gluer CC, Grampp S, Genant H (1997) Universal standardization of bone density measurements: a method with optimal properties for 
calibration among several instruments. J Bone Miner Res 12:1463-1470

24. Washburn RA, Smith KW, Jette AM, Janney CA (1993) The Physical Activity Scale for the Elderly (PASE): development and evaluation. J Clin Epidemiol 46:153-162

25. Baecke JA, Burema J, Frijters JE (1982) A short questionnaire for the measurement of habitual physical activity in epidemiological studies. Am J Clin Nutr 36:936-942

26. Block G, Subar AF (1992) Estimates of nutrient intake from a food frequency questionnaire: the 1987 National Health Interview Survey. J Am Diet Assoc 92:969-977

27. Block G, Hartman AM, Dresser CM, Carroll MD, Gannon J, Gardner L (1986) A data-based approach to diet questionnaire design and testing. Am J Epidemiol 124:453-469

28. Ahn Y, Kwon E, Shim JE, Park MK, Joo Y, Kimm K, Park C, Kim DH (2007) Validation and reproducibility of food frequency questionnaire for Korean genome epidemiologic study. Eur J Clin Nutr 61:1435-1441

29. Cummings SR, Cawthon PM, Ensrud KE, Cauley JA, Fink HA, Orwoll ES (2006) BMD and risk of hip and nonvertebral fractures in older men: a prospective study and comparison with older women. J Bone Miner Res 21:1550-1556

30. Mackey DC, Eby JG, Harris F, Taaffe DR, Cauley JA, Tylavsky FA, Harris TB, Lang TF, Cummings SR (2007) Prediction of clinical non-spine fractures in older black and white men and women with volumetric BMD of the spine and areal BMD of the hip: the Health, Aging, and Body Composition Study. J Bone Miner Res 22:1862-1868

31. Lau EM, Lee JK, Suriwongpaisal P, Saw SM, De Das S, Khir A, Sambrook P (2001) The incidence of hip fracture in four Asian countries: the Asian Osteoporosis Study (AOS). Osteoporos Int 12:239-243
32. Lim S, Koo BK, Lee EJ, Park JH, Kim MH, Shin KH, Ha YC, Cho NH, Shin CS (2008) Incidence of hip fractures in Korea. J Bone Miner Metab 26:400-405

33. Brownbill RA, Ilich JZ (2003) Hip geometry and its role in fracture: what do we know so far? Curr Osteoporos Rep 1:2531

34. Marshall LM, Zmuda JM, Chan BK, Barrett-Connor E, Cauley JA, Ensrud KE, Lang TF, Orwoll ES (2008) Race and ethnic variation in proximal femur structure and BMD among older men. J Bone Miner Res 23:121-130

35. Faulkner KA, Cauley JA, Zmuda JM, Landsittel DP, Nevitt MC, Newman AB, Studenski SA, Redfern MS (2005) Ethnic differences in the frequency and circumstances of falling in older communitydwelling women. J Am Geriatr Soc 53:1774-1779

36. Pollitzer WS, Anderson JJ (1989) Ethnic and genetic differences in bone mass: a review with a hereditary vs environmental perspective. Am J Clin Nutr 50:1244-1259

37. Nevill AM, Holder RL, Maffulli N, Cheng JC, Leung SS, Lee WT, Lau JT (2002) Adjusting bone mass for differences in projected bone area and other confounding variables: an allometric perspective. J Bone Miner Res 17:703-708

38. Looker AC (2002) The skeleton, race, and ethnicity. J Clin Endocrinol Metab 87:3047-3050

39. Reid DM, Mackay I, Wilkinson S, Miller C, Schuette DG, Compston J, Cooper C, Duncan E, Galwey N, Keen R, Langdahl B, McLellan A, Pols H, Uitterlinden A, O'Riordan J, Wass JA, Ralston SH, Bennett ST (2006) Cross-calibration of dual-energy $\mathrm{X}$-ray densitometers for a large, multi-center genetic study of osteoporosis. Osteoporos Int 17:125-132

40. Pearson D, Horton B, Green DJ (2006) Cross calibration of DXA as part of an equipment replacement program. J Clin Densitom 9:287-294 